\title{
Ergonomic sustainability based on the ergonomic maturity level measurement ${ }^{1}$
}

\author{
Mario Cesar Vidal ${ }^{\mathrm{a},}$, , Carmen Lucia Campos Guizze ${ }^{\mathrm{b}}$, Renato José Bonfatti ${ }^{\mathrm{c}}$ and Marcello \\ Silva e Santos ${ }^{\mathrm{d}}$ \\ ${ }^{a}$ Ergonomic Resarch Unit (GENTE/COPPE,) Production Engineering Program, Federal University of Rio de \\ Janeiro, Brazil. \\ ${ }^{\mathrm{b}}$ Production Engineering Department, Fluminense Federal University at Rio das Ostras Brazil. \\ ${ }^{c}$ Health and Environment Department, Fundação Oswaldo Cruz, Rio de Janeiro, Brazil. \\ ${ }^{d}$ Ergonomic Resarch Unit (GENTE/COPPE,) Production Engineering Program, Federal University of Rio de \\ Janeiro, Brazil.
}

\begin{abstract}
This paper aims at the application of an ergonomic maturity model (EMM), in order to assess the ergonomic sustainability outreach of ergonomic actions. This proposition was motivated by the widespread sensation that the development of the discipline, its educational devices and related practices depends on the attitude of ergonomics practitioners rather than environmental macroergonomic conditions. Maturity modeling in this paper is undertaken as a tool for ergonomic practitioners. Thus, its foundations were uprooted from diverse fields: Clinic Psychology, Quality Management and Project Management. The paper brings about a detailled explanation of this ergonomic maturity tool. The empirical part is fulfilled by the examination - using the EMM - of four emblematic cases excerpted from our research lab ergonomic portfolio.
\end{abstract}

Keywords: Macroergonomics, Strategy, Maturity, Sustainability, Conversational analysis.

\section{Prologue}

Ergonomics has been defined as a scientific discipline as well as a professional practice [23]. It is, in many countries an academic discipline in engineering, industrial design, psychology and so on. In these last decades, the ergonomic domain has surely been thriving. Nevertheless this growth is not as widely notoceable as expected, even though it was once being considered "work engineering" of the new millenium [13]. A question remains: since ergonomics is that great, why the businness world, operation operational engineers and managers are so far from ergonmics issues and its related methods?

The answers have intrigued the ergonomics professionals world, maybe uneffective in terms of translating theory to practice [3], inadequate design of training programs or maybe even their communication style is not suitable for corporate audiences [11]. Thus we will approach in this paper a comple- mentary point of view. The development of Ergonomics as a whole do not depend only on ergonomists attitudes, but it primarily relies on its general percolation in corporate environments in search of excellence. This excellence must be sustained by taking progressive steps both in organizational systems and in the ergonomic configuration within their strategies. In order to promote this joint development, it was essential to design a tool to assess the actual ergonomic - stage of an organization in which we are trying to intervene through ergonomic actions. The process will be explained as we lay the foundations and the framework of our ergonomis maturity model (EMM).

It is followed by an illustrative description of four emblematic cases drawn from a portfolio made out of 25 years of experience in developing Ergonomics research, practice and education in Latin America by the GENTE Lab [21].

\footnotetext{
${ }^{1}$ This paper was developed with partial sponsorship from CNPq and CAPES, brazilian research and education finacing agencies * Corresponding author.e -mail: mvidal@ergonomia.ufri.br. Av Horacio Macedo 2030, Centro de Tecnologia sala G-207 21941-914 Rio de Janeiro, Brazil.
} 


\section{Strategic approach of ergonomics}

Wilson [23] has pointed out the gap between theory - seen as consistent in terms of research development - and ergonomic practice, depicted as "craftsmanship" when it comes to the way it happens in the real world. Caple [3] predicts that ergonomics growth as a scientific discipline depends on the way its practitioners are able of transferring ergonomic findings arisen from the research field into ergonomic application in the companies. These authors synthesize a so called "attitudinal trend" among the set of ideas in ergonomics future development.

Unfortunately, current events and history have shown us that the evolution from craftsmanship to an evolved organizational vortex is based on dialectics between technical progress and social development, whose complementary path we propose to enhance in here. This path is largely influenced by changes in organizational and corporate cultures, including its safety and occupational hygiene aspects. A logical argument is that ergonomics is a sociotechnical approach. Therefore, the task of communicating, disseminating and placing ergonomics in the core of our society seems to be... sociotechnical!

On the other hand, we can easily and fully incorporate the challenge of proposing and disseminating methods for transferring and/or scaling up ergonomics at companies, communities and governments as a very much needed issue. We must understand though that the rate in which it will be perceived varies according to the current stage of concepts, practices, rites - and myths - of this or that organization. It is nowadays a common sense that stakeholders will better respond within their particular cultural setting. Finally Freire [7] says that the knowledge is necessary, but not sufficient to promote changes.

We sustain the need for special knowledge, concerning the place of ergonomics in the production scenario - and its relation to actual improvement of the workplace. Fortunately, we are not alone. Jenssen [14], about ten years ago, in his Nordic experience, noted that the simple availabilty of ergonomics principles and methods for operations planning and management rarely produce concrete effects in the real practice. This author underlined the existence of organizational preconditions, which conveys to a more important role as an organizational agent to an ergonomist.

This is an amazing issue, since the essence of this opinion was heard in the $1^{\text {st }}$. Brazilian congress of Ergonomics (Rio de Janeiro, 1974) from a series of invited lecturers, such as Brian Schaekel, from UK and Alain Wisner from France. It is also essential to remind the fundamental motto of Hal Hendrick's paper entitled "Good ergonomic is good economics".

However, this "battle" is not limited to Ergonomic Conferences, Research Laboratories and Technical Ergonomic Offices, but it has reached out to the corporate world as well. In such context, it is obvious that the corporate policies and guidelines depend on the CEO trend of thinking and the business strategy of the organization. As exposed by Dul \& Neumann, [5] In companies, ergonomics is typically linked to occupational health and safety (OHS) outcomes and to a company's obligation to fulfill OHS legislation, and therefore may be delegated to health and safety departments who are not connected to strategic decision making processes.

A great part of our investigation in Latin America [22], [23], merges into this general finding and its related issues:

a) Most of the programs prioritize safety over health issues.

b) The cases where ergonomics and quality programs are run together are still much less frequent than expected, which is more common among Brazilian enterprises than foreign ones.

c) The creation of a core team, a committee and other forms of disseminating alternatives, is still the more effective strategy.

d) Ergonomics is becoming a managerial matter and this seems to be a definite trend for contemporary enterprises.

e) Brazilian work enforcement authorities think ergonomics is the most effective way to regulate work organization within enterprises.

If we are truly convicted that ergonomics is an essential part of organizations' strategy, we should also agree that ergonomics should depart from a health paradigm toward a business one. Recent investigations [6] dealing with Ergonomics Programs have outlined some noticeable constraints such as lack of business-approach attitude, lack of focus on quality parameters and distancing from current practices of project management. Others researchers [1] have already expressed it, when dealing with back pain inhibiting program in a furniture industry in USA. According to this inquiry, more that $50 \%$ of interviewed workers pointed out organizational factors as the most impacting ones when it comes to overall performance. Somewhere between activists and warriors, Dul \& Neumann [5] list three arenas for promoting ergonomic in the enterprise: the purely corporate arena targeting the corporation and its stakeholders; the business strategy arena, gathering divi- 
sions like Human resources, Finances, Marketing, Industrial engineering and so on; the corporate policies arena, the emblematic example is the TQM program, adopted by a large set of organizations all around the world. Those corporate programs percolate throughout the various segmented areas of the enterprises and seem to be a very special arena for ergonomics to gain more significance in the organizational culture.

The mentioned papers of Dul \& Newmann also convey a large set of opportunities be be taken into those arenas. The core of this paper is to deal with particular difficulties of merging Ergonomics Teams and Company Officers' points of view in the formulation and all along the execution of a business contract. In other words we will try to approach some issues that are likely to occur no matter how well or poorly managed a contract is. In order to do so, two paths can be outlined: (i) to approach and to suggest materials and methods in order to minimize the lack of knowledge in raising possibilities by ergonomic actions, (as referred by Caple and others); (ii) to investigate, prior to the undertaking of ergonomic action, the current sociotechnical stage of organizations, which led them to specific strategic choices. Our choice turned on the second path.

\section{Toward a strategic frame for Ergonomics}

The emphasis we preach for dealing with this subject is poorly presented in current technical literature. This is not only due to the lack of materials and methods, but because we lack a business-oriented formulation of Ergonomics as a meaningful discipline. The reality of corporations' life, by means of a process overview within a systemic approach, requires an orientation both to its internal functioning as well as its organizational environment. The idea is to enhance continuity between public and corporate policies.

The definition of Torma-Krajewski et al. [20] of ergonomic process is adequated for our purposes: (...) an ergonomics process is defined as a formal, systematic application of ergonomics principles integrated with management systems and imbedded in the organizational culture. Under this definition, we can sustain that even registering some isolated ergonomic actions, the lack of Ergonomics structures produces a break in the program sequence, thus impacts the articulation of isolated projects for a significative change. The cited authors [21] underline that this also inhibits the launch of new ergonomic actions.

Since it is essential to create organizational structures for ergonomics in the organization, we should be able to deal with three aspects of management: process, project and permanence.

Process management has two different sections: Primarily to set up and maintain the tools employed for screening and reporting the current ergonomic stage of the various workplaces, equipments, softwares and organizational devices.

Project management as based on Project Management Institute definition: Project management is the structured set of tools for planning, organizing, securing, and managing resources to achieve specific goals. A project is a temporary endeavor with a defined beginning and end (usually time-constrained, and often constrained by funding or deliverables), undertaken to meet unique goals and objectives, typically to bring about beneficial change or added value.

Permanence management summarizes the sustainability of the ergonomic structure [26], due to the interdependence and the emerging complexity in the strategic dimension of organizations. It also underlines the singularity of each organizational culture as well as the eventual differentiation among subsystems of a corporation. This limits the possibilities of benchmarking strategies or good practices for different enterprises. In other words, to an ergonomic structure, permanence management aims to avoid loss of momentum and backlash.

The three targets of ergonomic management performed by a recently introduced structure cannot be taken as a simple matter into a corporation, one reason being the fact many of stakeholders could have been waiting for others structures, not exactly the chosen one. We must establish some foundations related to change management and ergonomics.

Wisner [26] noted that an organizational innovation should take into account the cultural patterns of whoever is receiving it. He proposed the notion of "anthropotecnologic island" to refer to the hyper standardization approach taken by some transnational corporations in order to ensure controlled performances of all their units. Not only this hyper control proved to be very expensive as a strategy, but the more detached from the holding, the greater is the frequency and diversity of production problems. The nature of problems was not limited to ethnic variables, but somewhat related to the cross-cultural field. In this sense, Brown Jr. [2] asked himself how to structure and manage organizations respecting technological advancement. He noted that, since this involves changes in the operational level, it is wise to rely on the - inner - local cultural base. It is emphasized that organizations are sociotechnical systems that are also structured as socio-cognitive systems 
[17]. This means that both decision-making and reliability are linked to technological and organizational bases. This is the issue of complexity in ergonomics and ergonomics of complex systems.

Useful for risk management, both the complex systems and macroergonomic issues do not fulfill a framework for business ergonomics. One solution is do not take technological systems and managerial ones could not be taken by independent parts of a production system [28].

\section{The content of a maturity approach}

This so called interdependence enhances a list of opportunities within organizations. Moreover, it outlines the different desiderata to public policies as well as a guideline for corporate policies. Thus, it delivers something else for coping with local business strategies. The new question evolves into the theme of the corporate singularity. The formulation becomes: where does the singularity factor come from? What kind of tools would be pertinent to approach it?

The Ergonomic Maturity Model (EMM) searches for those answers by merging applied and conceptual ergonomics along with Clinical Psychology and Psycho sociology. Then we revisit the concept of maturity, defined in Project Management practice as a measure of one's ability in promoting changes in an organization. This all merge into the change management concept phases (processes, project and permanence), helping us to establish a framework of critical relationships to ergonomic success.

The next step was to to handle these factors. By examining Clinical Psychology works [25] we see that maturity is a human property that requires at the same time development and losses (losing less functional stages for searching out to more developed degrees). Winnicot tells us that the information required to jump up to a higher step of maturity con- sists of a complete fulfillment of prerequisites of a lesser stage. In management, maturity was initially adopted by P. Crosby [4] who presented the Quality Management Maturity Grid. The scale proposed 5 maturity levels for business processes of the organization: (i) Uncertainty, (ii) Awakening, (iii) Enlightenment, (iv) Wisdom, (v) Certainty. This framework was adopted by the US military procurement office [13] in the development of a tool for selection of software development providers. Most projects were falling short on time and overrunning budget and financial estimates. It created the need to examine capacity degrees of service providers.

The maturity approach, here, takes a symmetric disposition. We set our tool set for an initial understanding of our future and/or current client, in terms of his capability in correctly working with ergonomics, more precisely with our ergonomic team. The earlier with address this concern, the less structural problems will arise in the course of a contract. This was our lucky bet, some years ago.

Currently, as defining Ergonomics as change management (processes, projects and permanence) we finally sustain that the ergonomic maturity assessment is a basic condition for realizing propositions like those set by Caple following the orientation of Dull and Neumann.

\section{Ergonomic maturity model (EMM)}

There are several maturity models being currently employed - CBP, PMMM, ESI INTERNATIONAL, CMM, PMI - OPM3. None of them have high degree of market dissemination, mainly due to poor broadcasting or communication of findings, results or all of that combined. Their general structure does not vary significantly. It is based on a measuring scale in a linear and vertically oriented structure (figure 1).

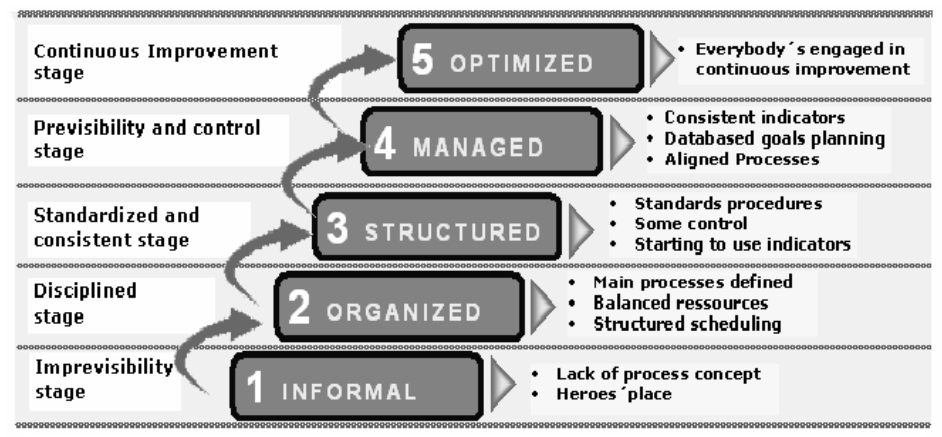

Figure 1: The general capability maturity model 
A specific frame for ergonomic maturity was initially created following two movements: (i) "holophrasing" the space problem of each capability level in terms of a project of change and (ii) unfold each holophrase according to the threes dimension of the Social Ecology (BOOKCHIN, 1980).

The effort for holophrasing was initially result of a through bibliographic research using maturity, change, management, project and sustainability as descriptors. This construction is described elsewhere [24]. The dimensions of social ecology [ ] taken into account were social justice, ecologic equilibrium and economic effectiveness. This unfolding operation establishes the three lines of external evaluation of an organization maturity level: practices, values and structures.

The organizational practice focuses the economic effectiveness avoiding bias that might compromise results for corporate overall sustainability during ergonomic intervention. The organizational values assess the concrete social responsibility levels in the organization, to outline one possible set of intervention protocols. For instance some forms of participation and tools can be incompatible to existing forms of social justice. Finally the themes of Ergonomics assess the real sustainability of ergonomic interventions, related to existing structures (table 1).

Table 1

Themes of interest in Ergonomic Maturity Scales

\begin{tabular}{|l|l|l|l|l|}
\hline \# & Typical Scenery & Sustainability & Labor culture & Ergonomics \\
\hline E & $\begin{array}{l}\text { Low interaction levels among } \\
\text { company's departments; }\end{array}$ & $\begin{array}{l}\text { Poor communication } \\
\text { among stakeholders }\end{array}$ & $\begin{array}{l}\text { Few or low level of Social } \\
\text { Responsibility actions }\end{array}$ & $\begin{array}{l}\text { No Ergonomic structure } \\
\text { and/or instances }\end{array}$ \\
\hline D & $\begin{array}{l}\text { Multiple projects, not yet inte- } \\
\text { grated through an ideal net- } \\
\text { work; }\end{array}$ & $\begin{array}{l}\text { Incipient change manage- } \\
\text { ment }\end{array}$ & $\begin{array}{l}\text { Social Responsibility actions } \\
\text { restricted to legal conformity }\end{array}$ & $\begin{array}{l}\text { Sensibilization and Con- } \\
\text { sciousness Plan in } \\
\text { progress }\end{array}$ \\
\hline C & $\begin{array}{l}\text { Implementation of an adequate } \\
\text { project management structure; }\end{array}$ & $\begin{array}{l}\text { Change management as } \\
\text { established leadership }\end{array}$ & $\begin{array}{l}\text { Social Responsibility going } \\
\text { beyond regulatory dimension }\end{array}$ & $\begin{array}{l}\text { Training Plan for com- } \\
\text { mitment }\end{array}$ \\
\hline B & Use of benchmarking actions; & $\begin{array}{l}\text { Projects related to Excel- } \\
\text { lence }\end{array}$ & $\begin{array}{l}\text { Ample Social Responsibility } \\
\text { corporate policy }\end{array}$ & Ergonomic Program \\
\hline A & Consolidation of best practices & Excellence Culture & Just Culture & Ergonomic Culture \\
\hline
\end{tabular}

The Ergonomic maturity measured by the existing and/or preempted troubles

The maturity themes shown in table 1 intend to enhance an overview of the maturity level in an organization. The idea is to enrich it with post-facto evaluations of problems brought up during a contract for ergonomic interventions.

Having such matrix on hands professional practitioners of ergonomics would be able to anticipate some "near problems". In consequence they can outline a pertinent strategy.

\section{Methodology}

This framework consisted in: (a) choice of representative cases; (b) pre evaluation of maturity level using the primary scale (table 1); (c) building a secondary scale (taxonomy of experienced troubles); (d) validate the new scale by specialists; and (e) application

a) Choice of representative cases
Four emblematic cases were chosen, from our consulting experience out of more than 20 eligible ones. The choice of these four cases is not as impregnated in logic criteria as we might like, but so is the lack of success cases in ergonomic literature. Likewise, the existence of published texts and technical reports upon difficulties and failures in realizing ergonomics intervention is practically inexistent. To overcome it, we decided to examine our own difficult reports, a practice in our consulting methods.

\section{b) Pre-evaluation of maturity level}

The evaluation processes happens in two moments, with a time gap of three months between the two evaluation sessions. Data gathered with a specific group of practitioners (related to one of the selected case) was confronted with their project manager's evaluation. The first set of evaluation sessions aimed at the classification of the organization-case in an ergonomic external maturity level. The four cases have been classified in terms of external maturity.

\section{c) Taxonomy of experienced troubles}

Ipso facto, we asked each group to examine a list of problems organized by the researchers. It was in- 
itially built using Crosby's capability grid. Each desideratum of this grid was linguistically translated into an operational problem by the researches. Then, this conceptual list was displayed to each practitioner. He/She could agree with an existing attribute, add a new one and also suggest discarding others, always based in the main difficulties in the contract he/she participated. This effort produced 14 categories, subdivided into 50 aspects.

Table 2

Maturity Trouble Matrix

\begin{tabular}{|c|c|}
\hline Maturity & Trouble-type in achieving a contract \\
\hline \multirow{4}{*}{$\begin{array}{l}\text { 1. Theme ac- } \\
\text { ceptation }\end{array}$} & 1.1 - Few knowledge about Ergonomics \\
\hline & 1.2 - Formal presentation of external team \\
\hline & 1.3 - Consciousness program schedule \\
\hline & 1.4 - Presentation of results to high management \\
\hline \multirow{4}{*}{$\begin{array}{l}\text { 2. Training of } \\
\text { the Ergonomic } \\
\text { external team }\end{array}$} & 2.1.- Aligning training \\
\hline & 2.2 - Diversity of competences \\
\hline & 2.3 - Quantitative evaluation skills \\
\hline & 2.4 - Qualitative evaluation skills \\
\hline \multirow{4}{*}{$\begin{array}{l}\text { 3. Client man- } \\
\text { ager training }\end{array}$} & 3.1 - Clarity of contracts \\
\hline & 3.2 - Low price strategy \\
\hline & 3.3 - Agile management \\
\hline & 3.4 - Ergonomic Management \\
\hline \multirow{3}{*}{$\begin{array}{l}\text { 4. Process } \\
\text { Standards }\end{array}$} & 4.1 - Report writing standards \\
\hline & 4.2 - Team structuring (previous vs. on-the-job) \\
\hline & 4.3 - Degrees of freedom \\
\hline \multirow{3}{*}{$\begin{array}{l}\text { 5. Organiza- } \\
\text { tional Struc- } \\
\text { ture } \\
\end{array}$} & 5.1 - Ergonomic committee? \\
\hline & 5.2 - Facilitation network? \\
\hline & 5.3 - Contents of consciousness program \\
\hline \multirow{4}{*}{$\begin{array}{l}\text { 6. Strategic } \\
\text { Planning }\end{array}$} & 6.1 - Ergonomic Project planning \\
\hline & 6.2 - Task-oriented team \\
\hline & 6.3 - Cost planning \\
\hline & 6.4 - Flexibility of goals \\
\hline \multirow{2}{*}{$\begin{array}{l}\text { 7. Continuous } \\
\text { Improvement }\end{array}$} & 7.1 - Segmentation of target divisions \\
\hline & 7.2 - Problem solving meetings \\
\hline \multirow{5}{*}{$\begin{array}{l}8 \text {. Ergonomics } \\
\text { Team - } \\
\text { Company's } \\
\text { Officers Rela- } \\
\text { tionship }\end{array}$} & 8.1 - Team integration \\
\hline & 8.2 - Cooperative report writing \\
\hline & 8.3 - Conflicts front-team versus back-office \\
\hline & 8.4 - Relationship team leader- team workers \\
\hline & 8.5 - Managerial style of the team leader \\
\hline \multirow{2}{*}{$\begin{array}{l}\text { 9. Corporate } \\
\text { Governance. }\end{array}$} & 9.1 - Availability of client employees \\
\hline & 9.2 - Pregnancy of tools in the specific enterprise \\
\hline \multirow{7}{*}{$\begin{array}{l}10 \text { - Leader- } \\
\text { ship }\end{array}$} & $10.1-$ Clear procedures \\
\hline & 10.2 - Interferences of client managers \\
\hline & 10.3 - Team management \\
\hline & $10.4-$ Tasks Delegation \\
\hline & 10.5 - Internal Communications \\
\hline & 10.6 - Operational adjustments \\
\hline & $10.7-$ Recognition by the team leader \\
\hline \multirow{3}{*}{$\begin{array}{l}11 \text {. Certifica- } \\
\text { tion }\end{array}$} & $11.1-$ Knowledge of ergonomic certification \\
\hline & $11.2-$ Skills for promoting ergonomics \\
\hline & 11.3-Certified Professional in teamwork \\
\hline \multirow{3}{*}{$\begin{array}{l}12 \text { Social Re- } \\
\text { sponsibility }\end{array}$} & 12.1 - Technical support by the team leader \\
\hline & 12.2 - Technical support by the contractor \\
\hline & 12.3 - Integration Contractor / ergonomic team \\
\hline \multirow{3}{*}{$\begin{array}{l}13 \text {. Organiza- } \\
\text { tional climate }\end{array}$} & $13.1-$ Client manager supporting \\
\hline & 13.2 -Convergence internal and external teams \\
\hline & 13.3 - Commitment with tactical level \\
\hline
\end{tabular}

\begin{tabular}{|l|l|}
\hline $\begin{array}{l}\text { 14. Informa- } \\
\text { tion Technolo- }\end{array}$ & $14.1-$ Learned lessons database \\
\cline { 2 - 2 } gy & $14.2-$ Use of ergonomic software \\
\cline { 2 - 2 } & $14.3-$ Electronic diffusion and broadcast \\
\hline
\end{tabular}

\section{d) Validation of the trouble matrix}

The obtained trouble matrix was validated by the involved project managers. The researchers performed a final adjustment in that scale. Table II shows the final trouble matrix used in the assessments.

\section{e) Application of the trouble matrix for ergonomic maturity measurement}

Having a methodological time lapse of three months, all the participants in the four projects were called to a set of assessment sessions.

The items in the list were organized as a chat script [23]. This procedure consists of a structured questionnaire, which is not directly presented to the inquired. The set of questions compose that conversation plan. The inquiry consists of a conversation upon the achievement of the contract, individually or in small groups (no more than three participants at a time). The researchers take notes on the overall conversation. In the end he/she fill up the answers in the questionnaire. This procedure avoids distortions, like understood poorly questions, inadequate answers and choice of a proposed option instead of an authentic answer. It also allows the possibility of registering answers to not formulated questions, which could be added $a d-h o c$.

\section{f) Data processing}

Data is obtained by means of Likert Scale logic (table 3)

Table 3

Scoring the answers

\begin{tabular}{|c|l|c|}
\hline \multicolumn{2}{|l|}{ Answers } & \multirow{2}{*}{$\begin{array}{c}\text { Score } \\
\text { (points) }\end{array}$} \\
\hline Option & Meaning & 10 \\
\hline a & Very important & 6 \\
\hline b & Just important & 2 \\
\hline c & Low importance & 0 \\
\hline d & Not important at all & \\
\hline
\end{tabular}

The entire set of results is then calculated using the indexation formula below:

$$
\left.I_{\text {mat }}=(P t s+100) / 100 \text { (eq. } 1\right)
$$

The results are interpreted according to table 4 
Table 4

Apuration of maturity level

\begin{tabular}{|l|l|}
\hline Score & Maturity level \\
\hline $\mathrm{I}_{\text {mat }} \leq 1.0$ & Informal \\
\hline $1.0<\mathrm{I}_{\text {mat }} \leq 2.0$ & Organized \\
\hline $2.0<\mathrm{I}_{\text {mat }} \leq 3.0$ & Structured \\
\hline $3.0<\mathrm{I}_{\text {mat }} \leq 4.0$ & Managed \\
\hline $\mathrm{I}_{\text {mat }}>4.0$ & Optimized \\
\hline
\end{tabular}

\section{Results}

Table 5 synthesizes the results of the application.

Table 5

EMM Application Results

\begin{tabular}{|l|c|c|c|c|}
\hline Organization & A & B & C & D \\
\hline 1. Theme acceptation & 16 & 24 & 14 & 28 \\
\hline 2. Training of the external team & 6 & 12 & 2 & 12 \\
\hline 3. Client manager training & 8 & 14 & 2 & 18 \\
\hline 4. Processes Standards & 8 & 14 & 14 & 18 \\
\hline 5. Organizational Structure & 22 & 26 & 18 & 36 \\
\hline 6. Strategic Planning & 0 & 14 & 14 & 16 \\
\hline 7. Continuous Improvement & 0 & 0 & 10 & 10 \\
\hline $\begin{array}{l}\text { 8. Ergonomics Team x Company Of- } \\
\text { ficers Relationship }\end{array}$ & 4 & 6 & 20 & 16 \\
\hline 9. Corporate Governability & 0 & 0 & 2 & 6 \\
\hline 10 - Leadership & 4 & 4 & 0 & 6 \\
\hline 11. Certification & 0 & 0 & 0 & 6 \\
\hline 12 Social Responsibilty & 6 & 6 & 10 & 10 \\
\hline 13. Organizational climate & 4 & 4 & 22 & 18 \\
\hline 14. Information Technology & 2 & 6 & 12 & 12 \\
\hline \multicolumn{1}{|c|}{ Maturity Level } & $\mathbf{1 . 8}$ & $\mathbf{2 . 3}$ & $\mathbf{2 . 4}$ & $\mathbf{3 , 1}$ \\
\hline
\end{tabular}

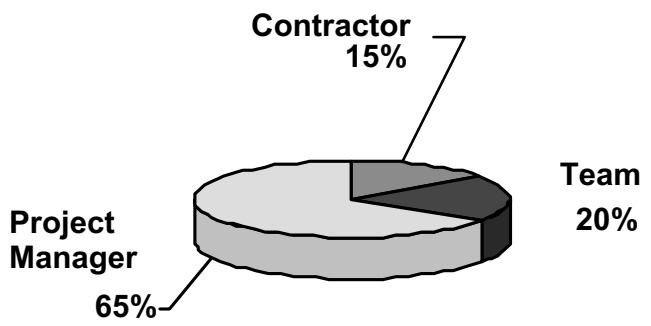

Figure 2 - Conflict raisers during ergonomic intervention

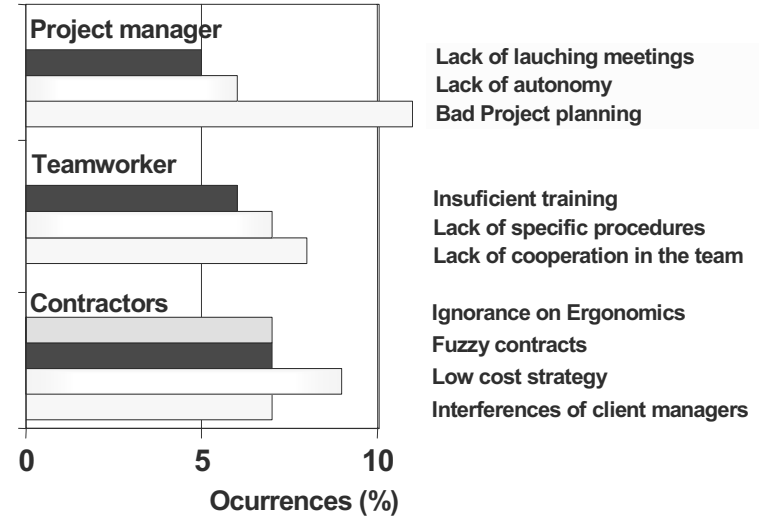

Figure 3 : Featured constraints when managing ergonomics contracts.

\section{Analysis}

In all selected cases the ignorance of ergonomics terminologies and its benefits seem to correlate with the lack of certified ergonomists in those companies. The more significant problems were related to a bad structure in terms of ergonomics dissemination in those corporations. This would confirm the essential annotations gathered in our revision [1], [7], [15], [29], especially the existence of ergonomic structures. The role played by the contract managers is always relevant as a problem source but mainly in the success of ergonomic actions.

In all those cases, process standards and strategic planning are strongly related to the final maturity level. It suggests some kind of cardinality between the troubles factors and corporate practices. A paradox appears when finding the case " $D$ ", the best one when evaluated in terms of ergonomic maturity. In this case the interference of local managers was most constant. Nevertheless, this was also the case in which the team leader was more significantly poorly evaluated in terms of his facilitation skills and core competencies. The case "B" corroborates this analysis because the success expressed by the participants is in good correlation with the team leader evaluation

This analysis ends with the indication of recommended ergonomic driven journeys. 
Table 6

Indications for driven journeys in all cases studied

\begin{tabular}{|c|l|l|}
\hline Case & Maturity & Strategic recommendations \\
\hline A & Organized & $\begin{array}{l}\text { To produce action plans for becom- } \\
\text { ing an structured corporation }\end{array}$ \\
\hline B & Structured & $\begin{array}{l}\text { To install a set of indicators for } \\
\text { helping ergonomic management }\end{array}$ \\
\hline C & Structured & To evaluate existing indicators \\
\hline D & Managed & $\begin{array}{l}\text { To organize a database of good } \\
\text { practices and lessons learned }\end{array}$ \\
\hline
\end{tabular}

\section{Discussion}

The differences between corporations with similar corporate maturity degree confirm the difficulty of searching for a number-synthesis for maturity consideration. This is the reason why we prefer to refer to the notion of levels. Nevertheless, we can see that the singularity may not be such a major problem. If we perform a detailed examination using similar references we can obtain relevant recommendations to an optimized organizational (re)design as well as enhance some subjects of prospective management actions. The strongest idea is to use ergonomic maturity models for feeding the ergonomic programs design.

Finally the contribution of ergonomics practitioners is widely exposed. Our intention is not only to fulfill our needs, but we are also looking forward for retro feeding the discussion about the future of ergonomics altogether.

\section{References}

[1]. Anema, J.R., Steenstra, I.A., Urlings, I.J.M., Bongers, P.M., Vroome, E.M.M., Van Mechelen, W. - Participatory ergonomics as a return-to-work intervention: A future challenge? American Journal of Industrial Medicine, Volume 44, 2003, pp. 273-281

[2]. Bookchin, M. (1995) [1990]. The Philosophy of Social Ecology, 2nd edition. Montreal, QC: Black Rose Books.

[3]. Brown Jr. O. (1991) - The origins and the concept of Macroergonomics. Proceedings of the $\mathrm{XI}^{\text {th }}$ Triennial Congress of the IEA. Taylor and Francis, London.

[4]. Caple, D. C. - The IEA contribution to the transition of Ergonomics from research to practice. Applied Ergonomics, Volume 41, Issue 6, October 2010, Pages 731-737. Special Section: Selection of papers from IEA 2009

[5]. Crosby, P. Quality is Free. McGraw-Hill., 1979. ISBN 007-014512-1

[6]. Dul J. and Neumann W. P. - Ergonomics contributions to company strategies Applied Ergonomics, Volume 40, Issue 4, July 2009, Pages 745-752

[7]. Entzel P., Jim Albers J. and Welch L. - Best practices for preventing musculoskeletal disorders in masonry: Stakehold- er perspectives. Applied Ergonomics, Volume 38, Issue 5, September 2007, Pages 557-566

[8]. Freire, P. - A pedagogy of make questions Paz e Terra, Rio de Janeiro, 1985.(In portuguese)

[9]. Garcia L.F. (2008) - Childhood, adolesecence or maturity? What is your business stage? In: http://www.administradores.com.br / noticias/ uploaded em 19/08/2008 - 00:03

[10]. Harrington, H. J. (1997) Total Improve management. Makron Books do Brasil Editora, São Paulo. (In portuguese)

[11]. Harrison P.D., Martins M. R.. Tsai L. W. (2006) - An aplication of the PMBooK maturity model. Proceedings of the XXVI Brazilian Congress on Production Engineering - Fortaleza, Brazil, October 2006, ABEPRO (In portuguese)

[12]. Hendrick, H. and Kleiner, B. (2006) Macroergonomia - Uma Introdução aos projetos de Sistema de Trabalho. Rio de Janeiro: Editora Virtual Científica.

[13]. Hendrick, H. (2008) Applying ergonomics to systems: some documented lessons learned. Applied ergonomics, vol.39, pp. 418-426.

[14]. Humphrey, W. S. (1990): Characterizing the Software Process: A Maturity Framework. (62-75) in T. DeMarco et al. (Eds.): Software State-Of-The-Art: Selected Papers. Dorset House Publishing.

[15]. Jensen P.L., Human factors and ergonomics in the planning of production International Journal of Industrial Ergonomics, Volume 29, Issue 3, March 2002, pp. 121-131.

[16]. Mafra, J. R. Economy of Ergonomics: costing methodology. D.Sc Thesis.,COPPE/UFRJ, Rio de Janeiro, RJ, Brasil.(in Portuguese)

[17]. Mussen, P. H.; Conger, J. H.; Kagan, J.; Huston, A. C. (1990) Development and personality of children. Ed. Harbra, São Paulo. (In Portuguese).

[18]. Pavard B. \& Decortis F. (1994) - Communication et Coopération: de la théorie des actes de langage à l'approche ethnometodologique. Em: Pavard B. (Org.) Systèmes coopératifs: de la modelisation à la conception. Octarès Edition, Toulouse

[19]. Prado, D. (2010) Maturity in project management. Nova Lima (MG). INDG Tecnologia e Serviços Ltda. (in Portuguese)

[20]. Sordi, J. O. (2008) Managing by processes: an approach of hodiern management. Ed. Saraiva. São Paulo. (In portuguese)

[21]. Stevens, S.N. (1999) - Definition of a maturity model Procedings of the 29th Anual PMI Congress - 1999

[22]. Torma-Krajewski, J. Steiner L., Lewis P., Gust P. and Johnson K. - Implementation of an ergonomics process at a US surface coal mine. International Journal of Industrial Ergonomics, Volume 37, Issue 2, February 2007, Pages 157-167

[23]. Vidal, M. C. R., Bonfatti, R. J. - Conversational Action: an Ergonomic Approach to Interaction In: Grant P. - Rethinking com municative interaction. Amsterdam : John Benjamin Publishing Company, 2003, p. 108-120

[24]. Vidal, M.C., Avancinni F. and Campos L.E. P. (2006) Anthropotecnology of ergonomics programs in Brazil. Proceedings of the XVI Triennial Congress of the IEA, Maastricht

[25]. Vidal, M.C.; Guizze, C.L.C; Mafra, J.R.; Bonfatti, R Vidal J.; Santos, M.S.; Pacheco, R.; Moreira, L.R. (2009) - The ergonomic maturity of a company enhancing the effectiveness of ergonomic process. XIV Triennial Congress of the IEA.

[26]. Wilson, J.R. (2000). Fundamentals of ergonomics in theory and practice. Applied Ergonomics, 31, 557-567.

[27]. Winnicott, D.W. (1990) - Home Is Where We Start from: Essays by a Psychoanalyst W W Norton \& Co Inc., London 
[28]. Wisner, A. (1985) - Organizational antropotechnological approach contingencies: an analithical approach. In: Bradley G.E. e Hendrick H.W. (Eds.) Human Factors in Organizational Design and Management. Elesier Science, 1994, 613617

[29]. Woodcock A. \& Denton H. The Teaching of Ergonomics in Schools: What is happening? IEA wbsite, http://www.iea.cc/ECEE/pdfs/woodcock_teaching_ergo.pdf, 08/23/2011, 01:14:40 PM.
[30]. Zink, K.J., Steimbler U. \& Fischer K. - Human Factors, Business Excellence and Corporate Sustainability: differing Perspectives, Joint Objectives In: Klaus J. Zink (Editor) Corporate Sustainability As A Challenge For Comprehensive Management, Springer-Verlag. New York, 2008. 